\title{
Gas Permeability of Thermoplastic Polyurethane Elastomers
}

\author{
Katsuji Matsunaga, ${ }^{\dagger}$ Kyoko SAto, Masahiro Tajima, and Yasuhiko Yoshida \\ Department of Applied Chemistry, Faculty of Engineering, Toyo University, \\ 2100 Kujirai, Kawagoe 350-8585, Japan
}

(Received December 3, 2004; Accepted March 7, 2005; Published June 15, 2005)

\begin{abstract}
We have studied the influence of the chemical structures of thermoplastic polyurethane elastomers (TPUs) on their permeability to carbon dioxide and oxygen. The gas permeability of a TPU was dependent on the chemical structures not only of the soft segments but also of the hard segments. A TPU whose soft segment consists of poly(oxytetramethylene) exhibited a higher carbon dioxide permeability than does a TPU with ester bonds in the soft segment. The introduction of poly(dimethylsiloxane) chains into the TPU markedly enhanced the carbon dioxide permeability. In a series of TPUs containing poly(oxytetramethylene)glycol (PTMG), the gas permeability increased with the chain length of the soft segments. In the dissolution-diffusion process of gas permeation, the diffusion process predominated. [DOI 10.1295/polymj.37.413]

KEY WORDS Thermoplastic Polyurethane Elastomer / Gas Permeability / Chemical Structure Dependence / Temperature Dependence /
\end{abstract}

Thermoplastic polyurethane elastomers (TPUs) are block copolymers composed of soft segments originating from polyol chains and hard segments produced by reactions between diisocyanates and chainextenders. Because the two kinds of segments are incompatible, they form a so-called microphase-separation structure. Further, the corresponding domains that the segments generate are responsible for a higher-dimensional structure of the TPU. The hard segment domain exhibits a crystalline phase due to an intermolecular cohesive force produced by hydrogen bonding of the urethane linkages, while the soft segment domain features weak intermolecular interactions and a high molecular mobility. The combination of these two types of domains form a higher-dimensional structure. The soft domain provides flexibility, while the hard domain prevents plastic deformation close to room temperature. In addition, the hard domain is plasticized by heating, and hardens again upon cooling.

Studies of the gas permeability of TPUs having these structures have already been reported. ${ }^{1-7}$ The relationship between gas permeability and chemical structure in these compounds, however, has not been well elucidated. The difficulty is due to the fact that, as mentioned above, TPU has a higher-dimensional structure differing from that of amorphous homopolymers such as poly(methyl methacrylate) and polystyrene.

The solubility, diffusivity and permeability (barrier capacity) of small molecules are very important properties of polymer materials from the viewpoint of their practical uses. In our laboratory, the fabrication of microcellular polyurethanes by the use of carbon dioxide is under study. ${ }^{8}$ The application of TPU to food packaging materials also is under study. Hence, we need a fundamental knowledge of the solubility of carbon dioxide in TPU and oxygen gas-barrier property of TPU.

In this paper, we discuss our investigation of the influence of the chemical structure of the TPUs on its carbon dioxide and oxygen gas permeability.

\section{EXPERIMENTAL}

\section{Materials}

For the studies of the influence of soft segments on gas permeability, five types of TPUs were provided by Dainichiseika Color and Chemicals Ltd., Japan. Their soft segments included poly(oxytetramethylene) (PTMG), poly(caprolactone) (PCL), poly(butylene adipate) (PBA), poly(hexamethylenecarbonate) (PC), and poly(dimethylsiloxane)-poly(oxytetramethylene) (PDSG-PTMG). Their structures and properties are shown in Figure 1 and Table I, respectively.

For the studies of the influence of PTMG chain length and hard-segment structure on gas permeability, we synthesized sample materials by the prepolymer method using a polyol: diisocyanate: chain-extender mole ratio of 1:4:3. The diisocyanates employed were hexamethylenediisocyanate (HDI), $m$-xylenediisocyanate (XDI), 4,4'-diphenylmethanediisocyanate (MDI); they were used as supplied commercially. For the chain-extenders, 1,3-propanediol (PD), 1,4butanediol (BD), and1,6-hexanediol (HD) were used as commercially provided (shown in Figure 2). The absence of a urea linkage in the TPUs obtained was

${ }^{\dagger}$ To whom correspondence should be addressed (E-mail: matunaga@eng.toyo.ac.jp). 


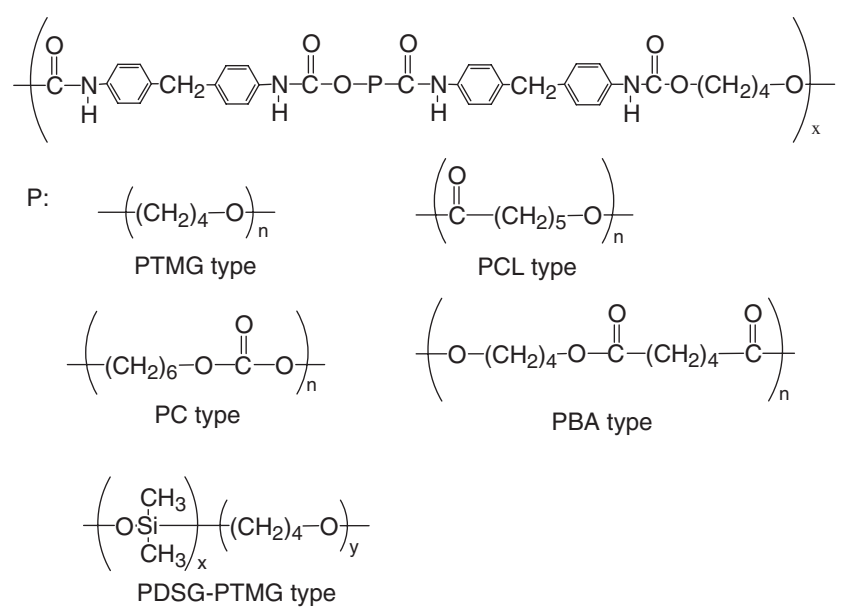

Figure 1. Chemical structure of provided TPUs.

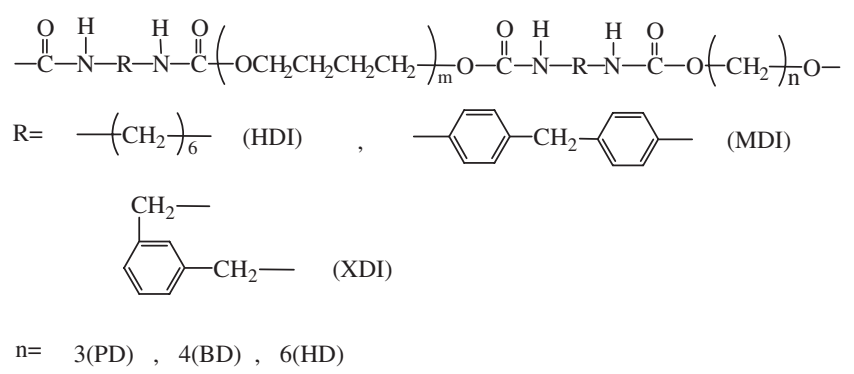

Figure 2. Chemical structure of synthesized TPUs.

confirmed by ${ }^{1} \mathrm{H}$ NMR, before their use in various physical measurements.

\section{Analyses}

The density was determined using electronic densimeter (Mirage Trading Co., Ltd., model SD-120L). The glass transition temperature of the soft segment $\left(T_{\mathrm{g}}\right)$ and the heat of fusion of the hard segment $\left(\Delta C_{p}\right)$ were determined using a differential scanning calorimeter (Seiko Electric Co., Ltd., model DSC220). The measurements were carried out with the samples sealed in aluminum cells at a nitrogen-gas flow rate of $50 \mathrm{~mL} / \mathrm{min}$ and a heating rate of $5^{\circ} \mathrm{C} / \mathrm{min}$. The polystyrene-reduced molecular weight $\left(M_{\mathrm{n}}\right)$ was determined by size-exclusion chromatography (SEC) using a Hitachi L-6000 pump, a L-3350 RI monitor and a Shodex KF-803 column. The crystallinity of the hard segment was examined with an X-ray diffractometer (Rigaku Co., Ltd., model RINT-1100).

\section{Gas Permeability Measurements}

Sample films with a thickness of $350 \mu \mathrm{m}$ were prepared with a hot press (Nisshin Kagaku Kogyo Co., Ltd., Japan, model HP-100TE). A film thus obtained was mounted on a differential pressure gas permeameter (Toyoseiki Co., Ltd., Japan, model MT-C1). After the measuring system was degassed for more than
Table I. Physical properties of provided TPUs

\begin{tabular}{lcccc}
\hline $\begin{array}{c}\text { Polyol type } \\
\text { of TPU }\end{array}$ & $\begin{array}{c}\text { Density } \\
\mathrm{g} / \mathrm{cm}^{3}\end{array}$ & $\bar{M}_{\mathrm{n}}{ }^{\mathrm{a}}$ & $\begin{array}{c}\mathrm{SP} \text { value } \\
\left(\mathrm{J} / \mathrm{cm}^{3}\right)^{1 / 2}\end{array}$ & $\begin{array}{c}T_{\mathrm{gg}}{ }^{\mathrm{c}} \\
\left({ }^{\circ} \mathrm{C}\right)\end{array}$ \\
\hline PTMG & 1.12 & 23900 & 18.4 & -40.9 \\
PCL & 1.18 & 21100 & 21.8 & -33.5 \\
PC & 1.21 & 19400 & 21.6 & -15.3 \\
PBA & 1.22 & 18600 & 22.6 & -23.4 \\
PDSG-PTMG & 1.13 & 42900 & 15.1 & -70.7 \\
\hline
\end{tabular}

a Polystyrene-reduced number average molecular wight ${ }^{\text {b Sol- }}$ ubility parameter of polyol estimated by Fedors's method ${ }^{9}$ ${ }^{\mathrm{c}}$ Glass transition temperature of soft segment

$24 \mathrm{~h}$ by a vacuum pump at a temperature controlled with a circulation thermostat, the gas permeability coefficient and diffusion coefficient were measured for oxygen and carbon dioxide. In general, eqs 1 and 2 hold for the gas permeability coefficient. ${ }^{10}$

$$
\begin{aligned}
& P=D S \\
& D=\frac{d^{2}}{6 t}
\end{aligned}
$$

Here, $P$ is the gas permeability coefficient (barrer), $D$ is the concentration-mean diffusion coefficient $\left(\mathrm{cm}^{2} \mathrm{~s}^{-1}\right), S$ is the solubility $\left(\mathrm{cm}^{3} \mathrm{~cm}^{-3} \mathrm{~cm} \mathrm{Hg}^{-1}\right), d$ is the film thickness (cm), and $t$ is the time (s) taken for diffusion.

\section{RESULTS AND DISCUSSION}

\section{Influence of Chemical Structure of Soft Segments}

Table II summarizes the results of the carbon dioxide permeability measurements at several temperatures in the range of $15-60^{\circ} \mathrm{C}$ for the TPUs shown in Figure 1. The permeability coefficient $(P)$ and diffusion coefficient $(D)$ of every sample material increased with a rise in temperature. In contrast, the solubility $(S)$ decreased increasing temperature. The TPUs containing PDSG-PTMG had the highest $P$, $D$ and $S$ values among the polyol-type samples examined. This property arises from the large free volume of the poly(dimethylsiloxane) component in the PDSG-PTMG, whose low polarity produces weak intermolecular forces. The TPUs whose soft segments have high calculated solubility parameters (Table I) show small $P$ values. Our results, however, were more complex. We found that $P$ tends to increase as the glass transition temperature ( $T_{\mathrm{gs}}$, Table I) of the soft segment falls. The $P$ values of the TPUs with carbonyl groups (PCL, PBA and PC) are smaller than those of the TPUs with ether bonds (PTMG and PDSGPTMG). In the former series, a strong interaction between the carbonyl group and the carbon dioxide appears to suppress the diffusion of the gas. These experimental results suggest that a higher permeability is shown by the sample material whose soft segment 
Table II. $\mathrm{CO}_{2}$ gas permeability, diffusivity and solubility of TPU films at a variety of temperatures

\begin{tabular}{|c|c|c|c|c|c|c|}
\hline $\begin{array}{c}\text { Polyol type } \\
\text { of TPU }\end{array}$ & & $15^{\circ} \mathrm{C}$ & $25^{\circ} \mathrm{C}$ & $40^{\circ} \mathrm{C}$ & $50^{\circ} \mathrm{C}$ & $60^{\circ} \mathrm{C}$ \\
\hline \multirow{3}{*}{ PTMG } & $P(\text { barrer })^{\mathrm{a}}$ & 8.49 & 11.2 & 22.0 & 28.6 & 35.5 \\
\hline & $D\left(10^{-7} \mathrm{~cm}^{2} \mathrm{~s}^{-1}\right)$ & 2.15 & 3.82 & 8.70 & 20.3 & 36.2 \\
\hline & $S\left(10^{-4} \mathrm{~cm}^{3} \mathrm{~cm}^{-3} \mathrm{~cm} \mathrm{Hg}^{-1}\right)$ & 39.4 & 29.4 & 25.3 & 14.1 & 9.80 \\
\hline \multirow{3}{*}{ PCL } & $P$ (barrer) & 3.13 & 5.57 & 11.1 & 14.8 & 21.7 \\
\hline & $D\left(10^{-7} \mathrm{~cm}^{2} \mathrm{~s}^{-1}\right)$ & 0.79 & 1.63 & 3.91 & 6.73 & 14.6 \\
\hline & $S\left(10^{-4} \mathrm{~cm}^{3} \mathrm{~cm}^{-3} \mathrm{~cm} \mathrm{Hg}^{-1}\right)$ & 39.7 & 34.1 & 28.4 & 22.0 & 14.9 \\
\hline \multirow{3}{*}{$\mathrm{PC}$} & $P$ (barrer) & 1.74 & 2.75 & 7.29 & 10.8 & 16.1 \\
\hline & $D\left(10^{-7} \mathrm{~cm}^{2} \mathrm{~s}^{-1}\right)$ & 0.49 & 0.92 & 2.66 & 4.79 & 7.81 \\
\hline & $S\left(10^{-4} \mathrm{~cm}^{3} \mathrm{~cm}^{-3} \mathrm{~cm} \mathrm{Hg}^{-1}\right)$ & 35.4 & 30.0 & 27.4 & 22.5 & 20.6 \\
\hline \multirow{3}{*}{ PBA } & $P$ (barrer) & 2.01 & 2.97 & 7.53 & 10.2 & 15.4 \\
\hline & $D\left(10^{-7} \mathrm{~cm}^{2} \mathrm{~s}^{-1}\right)$ & 0.48 & 1.02 & 2.90 & 5.20 & 12.6 \\
\hline & $S\left(10^{-4} \mathrm{~cm}^{3} \mathrm{~cm}^{-3} \mathrm{~cm} \mathrm{Hg}^{-1}\right)$ & 42.3 & 29.3 & 26.0 & 19.6 & 12.2 \\
\hline \multirow{3}{*}{ PDSG-PTMG } & $P$ (barrer) & 79.0 & 91.4 & 142 & 188 & 215 \\
\hline & $D\left(10^{-7} \mathrm{~cm}^{2} \mathrm{~s}^{-1}\right)$ & 13.6 & 21.7 & 53.8 & 202 & 207 \\
\hline & $S\left(10^{-4} \mathrm{~cm}^{3} \mathrm{~cm}^{-3} \mathrm{~cm} \mathrm{Hg}^{-1}\right)$ & 58.2 & 42.2 & 26.4 & 9.29 & 10.4 \\
\hline
\end{tabular}

has a lower cohesive energy, a weaker interaction with carbon dioxide, and a more vigorous Brownian movement at the temperatures studied.

\section{Temperature Dependences of Gas Permeability}

On the basis of the temperature dependences of $P$, $D$ and $S$ shown in Table II, we have obtained the activation energies of gas permeation $\left(E_{\mathrm{P}}\right)$ and diffusion $\left(E_{\mathrm{D}}\right)$, and the heat of solution $(\Delta H)$ using the Arrhenius eqs 3 and 4, and eq 5 (the Van't Hoff equation), respectively.

$$
\begin{aligned}
& P=P_{0} \exp \left(-E_{\mathrm{P}} / R T\right) \\
& D=D_{0} \exp \left(-E_{\mathrm{D}} / R T\right) \\
& S=S_{0} \exp (-\Delta H / R T) \\
& E_{\mathrm{P}}=\Delta H+E_{\mathrm{D}}
\end{aligned}
$$

Here, $P_{0}, D_{0}$ and $S_{0}$ are constants, $R$ is the gas constant, $T$ is the absolute temperature, $E_{\mathrm{P}}$ is the apparent activation energy of permeation, $E_{\mathrm{D}}$ is the apparent activation energy of diffusion, and $\Delta H$ is the apparent heat of solution. Table III provides a summary of

Table III. Activation energy (permeability: $E_{\mathrm{p}}$, diffusivity: $\left.E_{\mathrm{D}}\right)$ and heat of solution $(\Delta H)$ for $\mathrm{CO}_{2}$ gas permeability of TPU films

\begin{tabular}{lccc}
\hline $\begin{array}{c}\text { Polyol type } \\
\text { of TPU }\end{array}$ & $\begin{array}{c}E_{\mathrm{P}} \\
\left(\mathrm{J} \mathrm{mol}^{-1}\right)\end{array}$ & $\begin{array}{c}E_{\mathrm{D}} \\
\left(\mathrm{J} \mathrm{mol}^{-1}\right)\end{array}$ & $\begin{array}{c}\Delta H \\
\left(\mathrm{~J} \mathrm{~mol}^{-1}\right)\end{array}$ \\
\hline PTMG & 26.6 & 53.4 & -23.8 \\
PCL & 33.8 & 50.0 & -16.2 \\
PC & 40.6 & 50.0 & -19.5 \\
PBA & 37.1 & 56.4 & -9.39 \\
PDSG-PTMG & 19.0 & 53.2 & -34.3 \\
\hline
\end{tabular}

these results. As shown there, the $E_{\mathrm{P}}$ and $\Delta H$ values vary depending on the chemical structures of the polyols in the TPUs, while $E_{\mathrm{D}}$ is practically independent of the nature of the polyol components. Furthermore, in each type of TPU, the $E_{\mathrm{D}}$ value is larger than the $E_{\mathrm{P}}$ value, a result suggesting that the diffusion process is predominant in gas permeation.

In general, most of the urethane NH bonds in a TPU participate in intermolecular hydrogen bonds. The existence of the following three types has been reported. $^{12}$

(1) hydrogen bonding with urethane carbonyl groups

(2) hydrogen bonding with alkoxy oxygen atoms in urethane linkages

(3) hydrogen bonding with ether oxygen or carbonyl oxygen in soft segments

Types (1) and (2) form between hard segments, and type (3) between soft and hard segments. Our previous study has shown that types (1) and (2) overwhelmingly predominate over type (3), the proportion of which is less than a few percent. ${ }^{13}$ Notably, the density of the physical cross-links formed by hydrogen bonds is higher in the hard segments than in the soft segments. The energy of the type (3) hydrogen bond has been reported to be lower than the energies of types (1) and (2). The $E_{\mathrm{D}}$ values for carbon dioxide of poly(ethyl methacrylate) and polystylene are 33.1 and 36.4 $\mathrm{mol} / \mathrm{J},{ }^{11}$ values which are considerably smaller than the $E_{\mathrm{D}}$ values of every TPU studied here. This difference reflects the presence of intermolecular interactions due to hydrogen bonding in the TPUs. The large $E_{\mathrm{D}}$ values of the TPUs are also enhanced by the gas permeation that occurs mainly in the soft segments, and, moreover, by the fact that the hydrogen bond 
Table IV. Influence of soft segment length on $\mathrm{O}_{2}$ and $\mathrm{CO}_{2}$ gas permeability, diffusivity and solubility of $\mathrm{TPU}$ films at $25^{\circ} \mathrm{C}$

\begin{tabular}{|c|c|c|c|c|c|c|c|}
\hline \multirow{2}{*}{$\begin{array}{l}\bar{M}_{\mathrm{n}} \text { of } \\
\text { PTMG }\end{array}$} & \multirow{2}{*}{$\begin{array}{c}T_{\mathrm{gs}} \\
\left({ }^{\circ} \mathrm{C}\right)\end{array}$} & \multicolumn{3}{|c|}{$\mathrm{O}_{2}$} & \multicolumn{3}{|c|}{$\mathrm{CO}_{2}$} \\
\hline & & $\begin{array}{c}P \\
\text { (barrer) }\end{array}$ & $\begin{array}{c}D \\
\left(10^{-7} \mathrm{~cm}^{2} \mathrm{~s}^{-1}\right)\end{array}$ & $\begin{array}{c}S \\
\left(10^{-4} \mathrm{~cm}^{3} \mathrm{~cm}^{-3} \mathrm{~cm} \mathrm{Hg}^{-1}\right)\end{array}$ & $\begin{array}{c}P \\
\text { (barrer) }\end{array}$ & $\begin{array}{c}D \\
\left(10^{-7} \mathrm{~cm}^{2} \mathrm{~s}^{-1}\right)\end{array}$ & $\begin{array}{c}S \\
\left(10^{-4} \mathrm{~cm}^{3} \mathrm{~cm}^{-3} \mathrm{~cm} \mathrm{Hg}^{-1}\right)\end{array}$ \\
\hline 250 & -15.5 & 0.09 & 1.34 & 0.70 & 0.11 & 0.54 & 2.06 \\
\hline 650 & -27.3 & 1.30 & 2.79 & 4.65 & 2.66 & 0.89 & 29.8 \\
\hline 1000 & -37.8 & 2.11 & 4.12 & 5.12 & 8.32 & 3.22 & 25.9 \\
\hline 2000 & -63.5 & 7.12 & 26.6 & 2.68 & 26.8 & 10.3 & 26.0 \\
\hline 3000 & -74.1 & 11.7 & 32.1 & 3.64 & 29.0 & 12.3 & 23.5 \\
\hline
\end{tabular}

Table V. Influence of hard segment structure on $\mathrm{O}_{2}$ and $\mathrm{CO}_{2}$ gas permeability, diffusivity and solubility of TPU (used PTMG with $M_{\mathrm{n}}=2000$ ) films at $25^{\circ} \mathrm{C}$

\begin{tabular}{|c|c|c|c|c|c|c|c|}
\hline \multirow{2}{*}{$\begin{array}{c}\text { Hard } \\
\text { segment }\end{array}$} & \multirow{2}{*}{$\begin{array}{c}\Delta C_{p} \\
\left(\mathrm{~mJ} \mathrm{deg}^{-1} \mathrm{mg}^{-1}\right)\end{array}$} & \multicolumn{3}{|c|}{$\mathrm{O}_{2}$} & \multicolumn{3}{|c|}{$\mathrm{CO}_{2}$} \\
\hline & & $\begin{array}{c}P \\
\text { (barrer) }\end{array}$ & $\begin{array}{c}D \\
\left(10^{-7} \mathrm{~cm}^{2} \mathrm{~s}^{-1}\right)\end{array}$ & $\begin{array}{c}S \\
\left(10^{-4} \mathrm{~cm}^{3} \mathrm{~cm}^{-3} \mathrm{~cm} \mathrm{Hg}^{-1}\right)\end{array}$ & $\begin{array}{c}P \\
\text { (barrer) }\end{array}$ & $\begin{array}{c}D \\
\left(10^{-7} \mathrm{~cm}^{2} \mathrm{~s}^{-1}\right)\end{array}$ & $\begin{array}{c}S \\
\left(10^{-4} \mathrm{~cm}^{3} \mathrm{~cm}^{-3} \mathrm{~cm} \mathrm{Hg}^{-1}\right)\end{array}$ \\
\hline HDI-BD & 0.034 & 27.5 & 77.0 & 3.57 & 63.9 & 25.8 & 24.8 \\
\hline XDI-BD & 0.051 & 6.84 & 18.1 & 3.79 & 34.2 & 10.7 & 31.9 \\
\hline MDI-PD & 0.077 & 5.48 & 14.5 & 3.77 & 22.1 & 7.33 & 30.2 \\
\hline MDI-BD & 0.069 & 6.21 & 33.9 & 1.83 & 26.1 & 8.73 & 29.9 \\
\hline MDI-HD & 0.229 & 3.44 & 13.4 & 2.57 & 15.6 & 5.26 & 29.7 \\
\hline
\end{tabular}

energy in the soft segments is low and strongly temperature-dependent.

\section{Influence of the Soft-segment Chain Length}

To clarify the influence of the soft-segment chain length on gas permeation, we have determined the carbon dioxide and oxygen permeability coefficients for TPUs having different number-average PTMG molecular weights. The results are summarized in Table IV. The permeability coefficients rise as the soft-segment chains lengthen. The diffusion coefficients $(D)$ of both gases depend on the chain length of the soft segments, which is a tendency similar to that observed for the gas permeability coefficients. In contrast, the solubilities $(S)$ of these gases do not change significantly with the soft segment chain length, except for PTMG with $M_{\mathrm{n}}=250$. Such behaviors, found for many polymers, are even exhibited by TPU, which is composed of soft- and hard-segment phases. The exception found for PTMG with $M_{\mathrm{n}}=$ 250 is presumably caused by the fact that the density of cross-links is much higher than the other TPUs. This occurs because the chain length of the soft segment is shorter than that of the hard segment (its molecular weight is 340 which is the sum of the molecular weights 250 of MDI and 90 of BD).

\section{Influence of the Chemical Structure of the Hard Seg- ment}

Although the soft phase, having weak intermolecular interactions, plays the major role in the gas permeation of a TPU regardless of whether it consists of only soft phase or of both soft phase and hard seg-

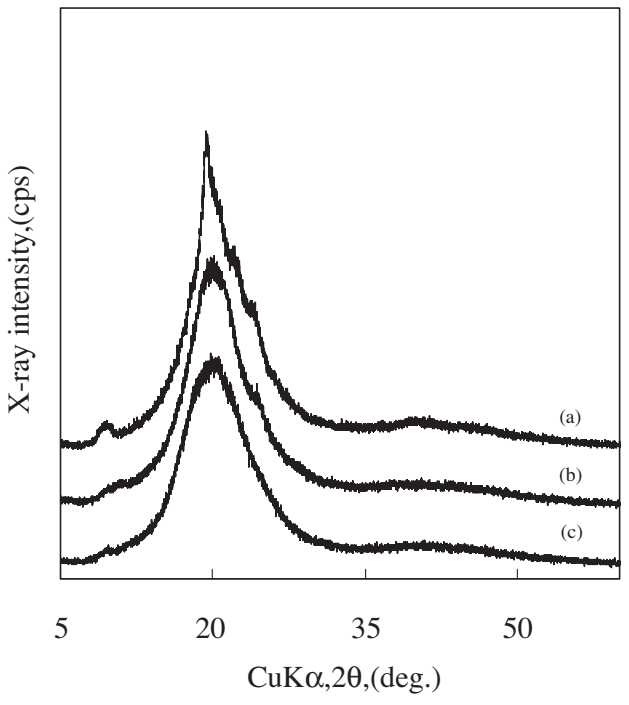

Figure 3. X-Ray diffraction patterns of TPUs (a) MDI-1,6HD (b) MDI-1,3PD (c) MDI-1,4BD.

ment, the effect of the chemical structure of the hard segment on gas permeation is also worth examination. As shown in Table $\mathrm{V}$, the solubility is independent of the chemical structure of the hard segments, a result also observed for the soft segments. However, in the HDI-BD system incorporating aliphatic hexamethylenediisocyanate, the diffusion coefficients of the carbon dioxide and oxygen are high; consequently, the gas permeability coefficients are markedly elevated. The gas permeability coefficients of the TPUs prepared from aralkyl diisocyanates are higher than those of the other aromatic diisocyanate-based TPUs. For the MDI-HD-based TPU, the oxygen and carbon 
dioxide permeability coefficients are low. The difference specific heat capacity $\left(\Delta C_{p}\right.$ in Table $\left.\mathrm{V}\right)$ of the MDI-HD based hard segment is considerably larger than the values of the hard segment composed of other diisicyanates and diols. Because of its crystallinity, presumably, the MDI-HD system has a high packing density. Evidence for this supposition comes from the $\mathrm{X}$-ray diffraction patterns (shown in Figure 3), in which the peaks characteristic of the crystalline phase are sharper in the MDI-HD system than in the MDIPD and MDI-BD systems.

\section{CONCLUSIONS}

We have investigated the influence of the chemical structures of thermoplastic polyurethane elastomers (TPUs) on the permeability of oxygen and carbon dioxide. The results are summarized as follows:

(1) The TPU whose soft segment consisted of poly(oxytetramethylene) (PTMG) showed a higher carbon dioxide permeability than the TPUs with ester linkages.

(2) The introduction of a poly(dimethylsiloxane) chain to the TPU significantly enhanced the carbon dioxide permeability.

(3) In the TPUs incorporating PTMG, an increase in the soft segment chain length resulted in a rise in the gas permeability.

(4) In the dissolution-diffusion process of gas permeation in the TPUs, the diffusion process was predominant.

(5) The gas permeability depended on the chemical structures of both the soft segments and the hard segments.

\section{REFERENCES}

1. H. Xiao, Z. H. Ping, J. W. Xie, and T. Y. Yu, J. Appl. Polym. Sci., 40, 1131 (1990).

2. K. H. Hsieh, C. C. Tsai, and S. M. Tseng, J. Membr. Sci., 49, 341 (1990).

3. G. Galland and T. M. Lam, J. Appl. Polym. Sci., 50, 1041 (1993).

4. L. S. Teo, J. F. Kuo, and C. Y. Chen, J. Appl. Polym. Sci., 59, 1627 (1996).

5. H. B. Park, C. K. Kim, and Y. M. Lee, J. Membr. Sci., 204, 257 (2002).

6. C. P. Chwang, S. N. Lee, J. T. Yeh, C. Y. Chen, and D. Y. Chao, J. Appl. Polym. Sci., 86, 2002 (2002).

7. Z. F. Wang, B. Wang, Y. R. Yang, and C. P. Hu, Eur. Polym. J., 39, 2345 (2003).

8. S. Ito, K. Matsunaga, M. Tajima, and Y. Yoshida, Polym. Prep., Jpn., 53, 5609 (2004).

9. R. F. Fedors, Polym. Eng. Sci., 14, 147 (1974).

10. R. M. Barrer, Trans. Faraday Soc., 35, 628 (1937).

11. J. Brandrup and E. H. Immergut, "Polymer Handbook," 2nd ed., John Wiley \& Sons, New York, N.Y., 1975, p III-229.

12. Z. S. Petrović and J. Ferguson, Prog. Polym. Sci., 16, 695 (1991).

13. K. Matsunaga, M. Oumi, M. Tajima, and Y. Yoshida, Nippon Kagaku Kaishi, 363 (2001). 